\title{
Bilateral Sacroiliitis Induced by Systemic Isotretinoin Treatment
}

The Editor,

Sir,

A 32-year-old woman was admitted with inflammatory low back and hip pain for the last two weeks. In her medical history, she had been using systemic isotretinoin treatment for the last two months (first month $20 \mathrm{mg} / \mathrm{day}$, second $30 \mathrm{mg} /$ day) for acne vulgaris. On physical examination, she did not have decreased axial range of motion. Sacroiliac tests were negative. There were no enthesopathy, peripheral joint involvement, ocular findings, cutaneous lesions indicating seronegative spondyloarthritis or infection. C-reactive protein and erythrocyte sedimentation rate were normal and HLAB27 was negative. A sacroiliac radiograph showed sclerosis at the inferior parts of the iliac and sacral wings bilaterally (Fig. 1).

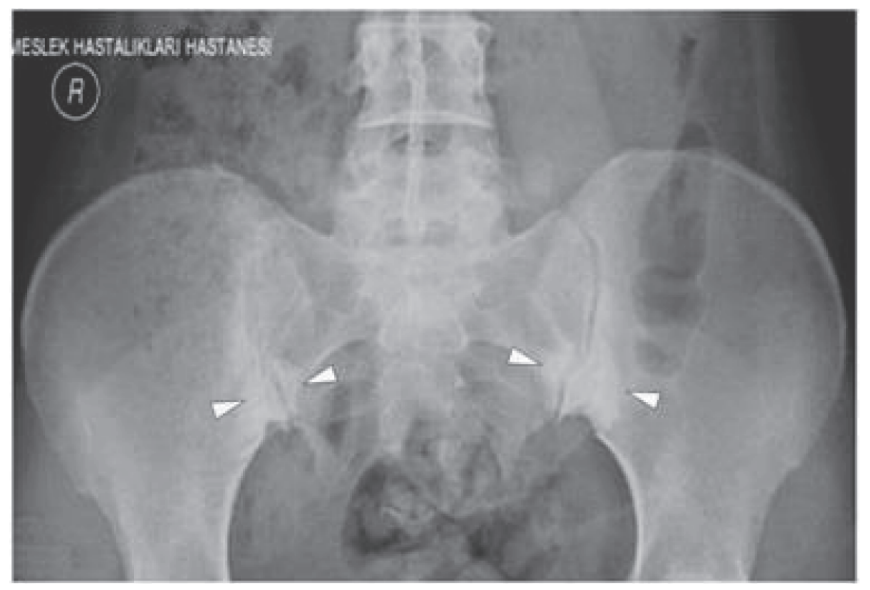

Fig. 1: Anterior-posterior pelvis radiograph demonstrates sclerosis at the inferior parts of the iliac and sacral wings bilaterally.

Magnetic resonance imaging showed increased signal intensity and bone marrow oedema of the sacroiliac joints bilaterally (Fig. 2).

The patient was eventually diagnosed with sacroiliitis induced by isotretinoin treatment. Isotretinoin was stopped and oral indomethacin $75 \mathrm{mg}$ /day was commenced. Clinical improvement was apparent two weeks later.

Systemic retinoids are commonly prescribed for the treatment of severe acne vulgaris. However, they have some side effects (1), sacroiliitis being rare (2-7). Until now, isotretinoin induced sacroiliitis has been documented in a limited number of patients and in most of them it was bilaterally $(2-7)$. Likewise, herein we have reported a case of bilateral sacroiliitis due to isotretinoin and highlighted the rigorous follow-up for the musculoskeletal side effects of isotretinoin.

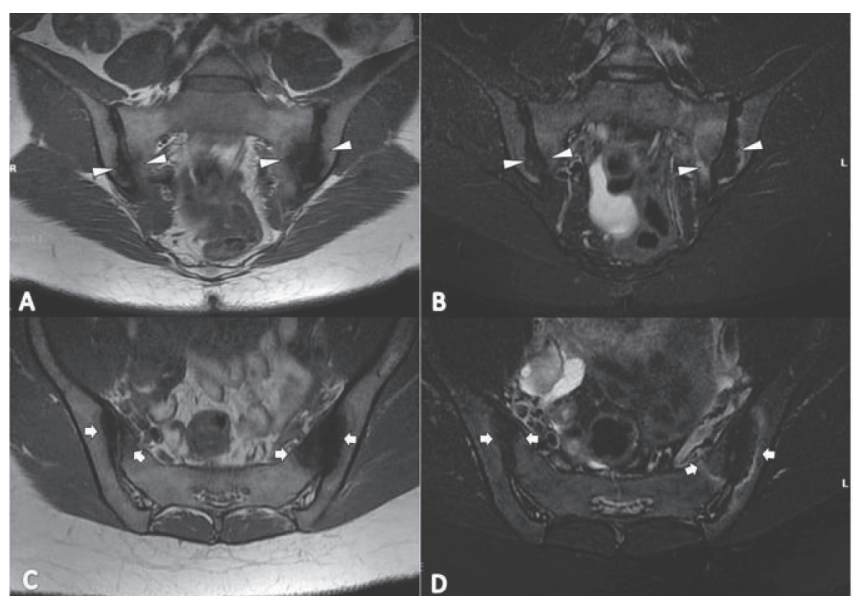

Fig. 2: Magnetic resonance images illustrate increased signal intensity and bone marrow oedema of bilateral sacroiliac joints in T1-weighted coronal (A) and axial (C) views, and STIR coronal (B) and axial (D) views.

Clinical manifestations of sacroiliitis become prominent after three weeks to three months of isotretinoin therapy $(2,3)$. However, aetiopathogenesis of isotretinoin-induced sacroiliitis still remains unclear. Hypersensitivity and increased T-cellular immune response might be the underlying mechanisms. Furthermore, isotretinoin was found in the synovial fluids (5). Matrix metalloproteinase activity might be stimulated by isotretinoin eventually causing membrane degradation (2). Acute phase reactants (erythrocyte sedimentation rate, C-reactive protein) are expected to increase in sacroiliitis $(3,4)$. As for the imaging methods; X-rays and computed tomography can detect widening and erosions in the sacroiliac joints. Magnetic resonance imaging and bone scintigraphy are quite sensitive to show bone marrow oedema and increased signal uptake $(4,5)$. Treatment of sacroiliitis induced by isotretinoin comprises withdrawal of the isotretinoin, anti-inflammatory drugs (non-steroidal/steroidal) and immunosuppressive agents for the severe sacroiliitis $(2,6)$.

Isotretinoin-induced sacroiliitis can cause severe pain, disability and affect quality of life adversely (3). Herewith, we would like to highlight the fact that low back and/or hip pain should alert one to sacroiliitis in relevant patients under systemic retinoid treatment. Hence, relevant patients necessitate rigorous follow-up for prompt diagnosis.

Keywords: Acne vulgaris, low back pain, retinoic acid, sacroiliitis

MT Yıldızgören ${ }^{1}$, T Ekiz ${ }^{2}$, AA Karataş Toğral ${ }^{3}$

From: ${ }^{1}$ Department of Physical Medicine and Rehabilitation, Ankara Occupational Diseases Hospital, ${ }^{2}$ Department of Physical Medicine and Rehabilitation, Ankara Physical Medi- 
cine and Rehabilitation Training and Research Hospital, and ${ }^{3}$ Department of Dermatology, Ankara Occupational Diseases Hospital, Turkey.

Correspondence: Dr T Ekiz, Türkocağ St, 6 Ankara Fizik Tedavi ve Rehabilitasyon Eğitim ve Araştırma Hastanesi, 06230, Ankara, Türkiye. Fax: +9031231180 54, e-mail:timurekiz@gmail.com

\section{REFERENCES}

1. Yıldızgören MT, Karataş Toğral A, Baki AE, Ekiz T. Effects of isotretinoin treatment on cartilage and tendon thicknesses: an ultrasonographic study. Clin Rheumatol. 2015; 34: 1255-58.

2. Levinson M, Gibson A, Stephenson G. Sacroiliitis secondary to isotretinoin. Australas J Dermatol 2012; 53: 298-300.
3. Rozin AP, Kagna O, Shiller Y. Sacroiliitis and severe disability due to isotretinoin therapy. Rheumatol Int 2010; 30: 985-86.

4. Eksioglu E, Oztekin F, Unlu E, Cakci A, Keyik B, Karadavut IK. Sacroiliitis and polyneuropathy during isotretinoin treatment. Clin Exp Dermatol 2008; 33: 122-24.

5. Bachmeyer C, Charoud A, Turc Y, Callot V, Blum L, Aractingi S. Isotretinoin-induced bilateral sacroiliitis. Dermatology 2003; 206: 285 86.

6. Barbareschi M, Paresce E, Chiaratti A, Ferla Lodigiani A, Clerici G, Greppi F. Unilateral sacroiliitis associated with systemic isotretinoin treatment. Int J Dermatol 2010; 49: 331-33.

7. Çakır T, Subaşı V, Bilgili A, Demirdal ÜS, Ülker RN. A case with bilateral sacroiliitis and polyneuropathy development due to isotretinoin use. Arch Rheumatol 2014; 29: 304-308. 